曲り円管内の層流速度助走区間の可視化

$$
\begin{gathered}
\text { 宇都宫大・工 秋山光庸，花調嘉明，浦井勇 } \\
\text { 鈴木道㧴，K.C.Cheng }
\end{gathered}
$$

VISUAL STUDY OF LAMIMAR FLOW IN THE ENTRANCE, REGION OF A CURVED PIPE

Mitsunobu AKIYAMA*, Yoshiaki HANAOKA*, Isamu URAI*

Michiyoshi SUZUKI* and K. C. CHEMG ${ }^{* *}$

\begin{abstract}
Three-dimensional laminar-flow development in a curved pipe has been investigated by using flow visualization technics. The hydrogen bubble andithe powder of pumice used in Japanese painting were applied to traice the main and secondary flows, respectively. The thermal and refraction compensators were found to be needed for improved results. The results are obtained for the locations at $0^{\circ}, 22.5^{\circ}, 45^{\circ}, 90^{\circ}$ and $180^{\circ}$ from the beginning of the curved pipe led by a long leading straight pipe under the flow conditions of Reynolds number 1000, Dean number 333 and the curvature ratio to be of $\pi / 9$. As a result, the overshooting phenomenon of the main flow distortion towards the outer wall due to the centrifugal force in the midst of the development is clearly identified and an overall comparion is made with the available theoretical results in good agreement.
\end{abstract}

1 はじめに

直円管内で十分に発途レた層流を同一径の曲り管に道入して，曲わからくる遠 心゙力によって生に゙る流速分布の発違の椂子を可視化法により調べた。水流の可 視化には水素気沦法と日本画材用の㪕石粒子とを，そ心ぞ水主流飞䊣断面上a二 次流水に用いて観察・撮影した。それらの写真により，流水が曲管へ流入して から発逢するまでの各段階における速度分布の特徵をとらえることが出来にので, その概要を報告する。理論計算も現在進行中でヌり，それウとの比鄣について も述べる。

\title{
2 本实験の概要と特徵
}

本实験装遺の直管道入部は内径 $2 a=48 \mathrm{~mm}$ ，長さ400 cm であり，試験部は同 一内径で管中心曲率半径 $R_{c}=21.6 \mathrm{~cm}$ の曲管である。また撮影位置は曲管入口 部より $0^{\circ}, 22.5^{\circ}, 45^{\circ}, 90^{\circ}$ おび $180^{\circ} と し た 。$ 使用した条件はレイ/ルズ数

* Dept. of Mech. Engg., Fac. of Engg., Utsunomiya Univ., Ishii cho, Utsunomiya 321, Japan

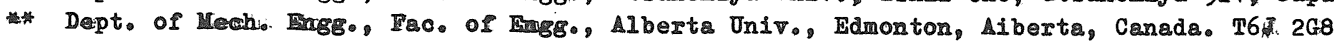


$\operatorname{Re}=1000, i>\tau^{\prime \prime} \operatorname{Re}=\bar{W} 2 a / \nu$,

$\bar{W}$ :平圴流速, $2 a$ : 管直径, $\nu$ : 動粘性係数, ディーン数 $D_{e}=$ 333, ¿ > おむび曲率半径比 $a / R_{c}=1 / 9$ を 用いた。(因1 と図2を参照) 本实験は次の事柄に特徵が西 る。

（1）主流の可視化には一般的 な水素気沦法を用いたが，電極 の白金線を管中心曲率線上で測 定位置より上流 $20 \mathrm{mmaところ}$

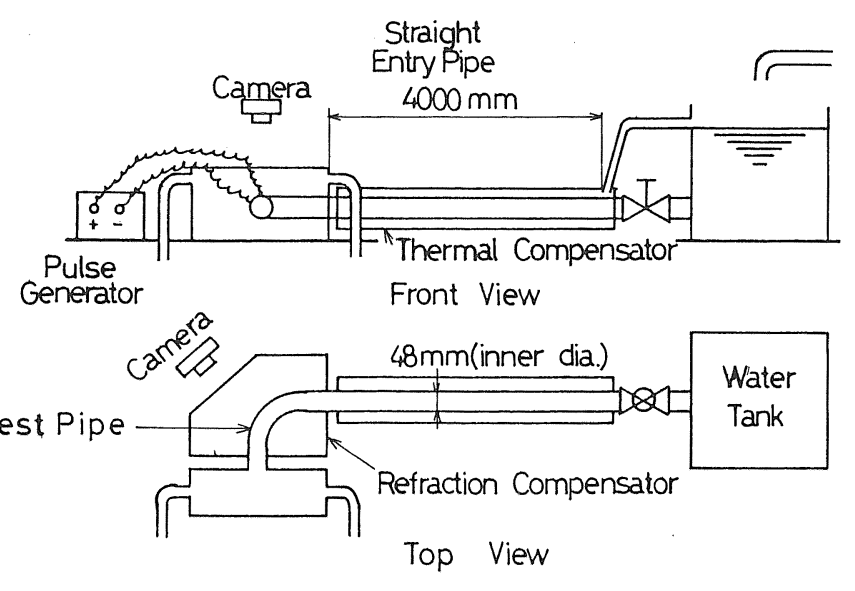

Fig.1 Test Apparatus (Main Flow) に設定( 2 測定位置の誤差をで きる限り少なくした。

(2) 二次流水については固体 粒子トレーサのうち適当なもの として軽石粉末を用いた。う れは嵩比重 0.83 と軽いが水に入 北ると水中によく浮遊しており，

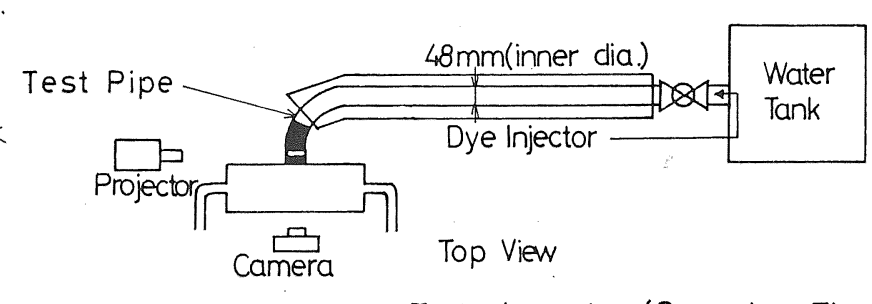

Fig.2 Test Apparatus (SecondaryFlow)

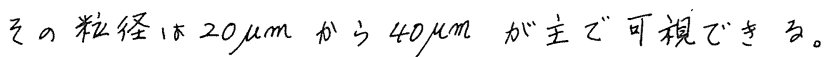

(3)内管内の水流を外部から撮影するには管壁による层折率による歪みを補正 することが重要であり、これには箱型水槽を用いることで解決している。

(4) 撮影を容易にするため供試管径は大きいが、この上に室温と水温とに大き な差がでれば浮力の影永が管内流に現わ水自然对流が発生する。その結果, 歪 んだタイムラインが観测された。之比を改良才るために, 供試水を円管外側に 設けた水槽にバィパスレて室温による加熱を防立, 管の出入口の水温差を0.02 C 以内におさめた。

\section{3 主流速度分布の結果と考察}

主流方向速度分布を入口かうの角度により分けて䝨次因了，4おまび5に示す。 四中（（）が水平方向速度分布にあたり，二の写真の左側が曲管の内迥り側で，右 側が外迥り側を皂してぬる。（b）は重直方向速度分布を示し，左側が下部，右 側が上部を示す。四では秀さ妓，直円管内で十分に発達した点での水平方向 と重直方向の速度分布も求也放物形分布を礁認した。二の放物形速度分布が曲

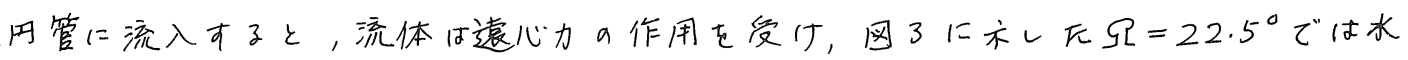

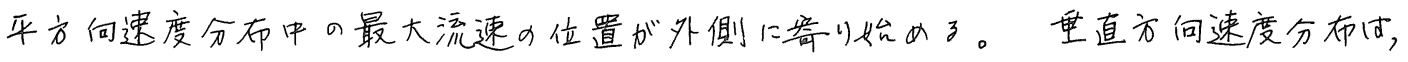


流れの対称性も失なわれることもなく、また最大速度点も管中央に西子。

因4は曲管入口上り $45^{\circ}$ 位置のものである。ここに至ると, 水平方向速度分 布は最大速度部が極度に管外迴り侧に寄り，内迴り侧の低速部は管中心部にまで 及んでくる。重直方向速度分布は今までと異なり上下両端に最大流速を持つな うにな，中央部の速度は $\Omega=22.5^{\circ}$ の場合に比べ低下している。曲管内で遠 心为は主流速度の強さの二集に比例して作用する。放物形の速度分布で曲管に。 流体が流入すれば，断面の中心゙部分で遠心゙力は最大となり，これが流体の粘性摩 擦力と压力との均衡を保っように写真に見うれる主流速度を形成する。ここで は管の内迴り部の流体を置き去りにして，主流中心部の流体は流体自身が持っそ の慣性力で管の外建り部へ寄世られて行き, 最後には管中心゙部の主流速度自身が 極小值を持つような行き過ぎ現象を起こしていることが磪認される。これが水 二900の四5になると, この行き過き”除々に回復して全体的になめうかな安定し た速度分布へ向う。的様にして速度分布が安定して一定形状を示可までの速 度助走区闃長士が定まる。十お，重直方向速度分布测定では、二次流水、影櫭 を受け易く中心゙部では夕イムラインが滑をまくように卷き込ま必る現象がみられ

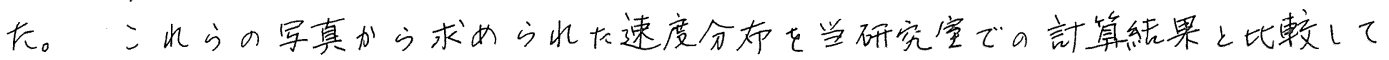
良⼀一致を兒た。

(主流用実験条件) 水素気泡用直流パル人発生置; パル人周期 $T=400 \mathrm{~ms}, 11^{\circ}$ 几人幅 $a=10 \mathrm{msec}$, 光源; $120 \mathrm{~V}, 42.3 W_{S}$ ，露光；1/60 Sec, F.8.0，7ィルム;

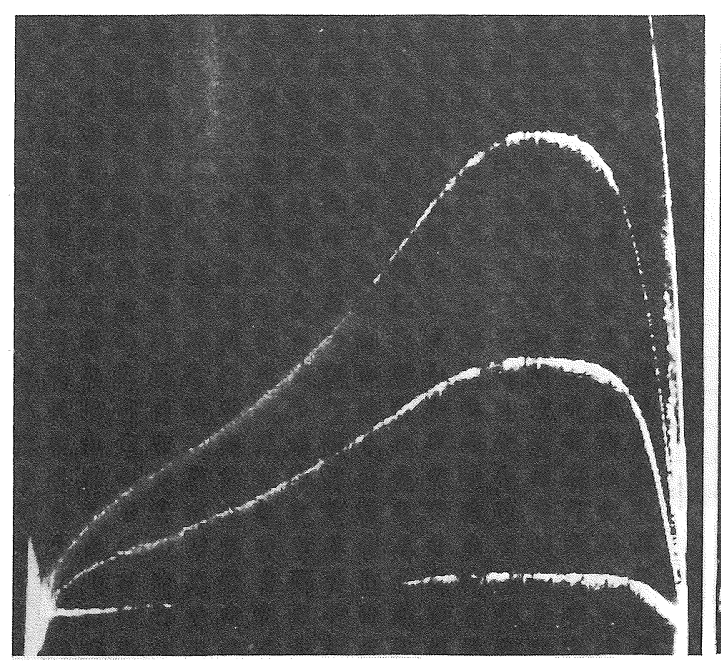

Inner Side

(a)Horizontal Direction

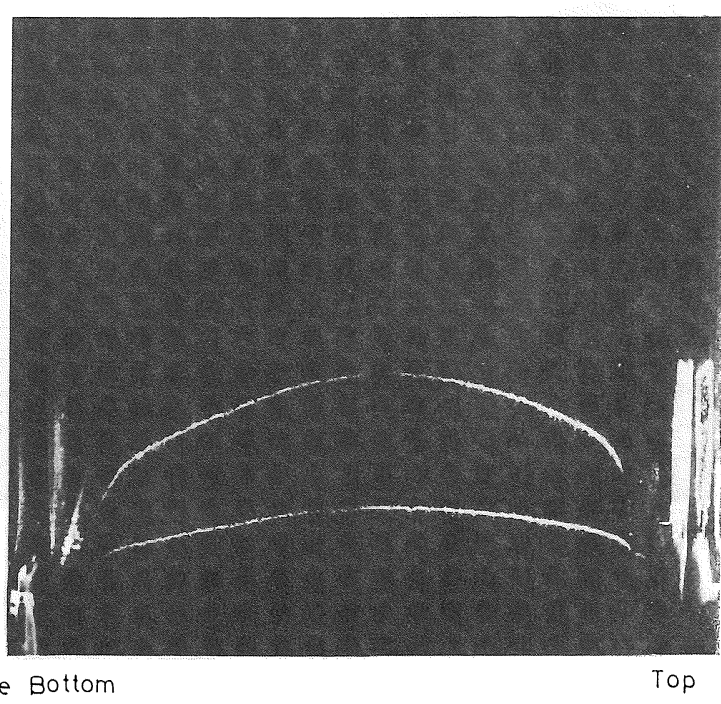

(b) Vertical Direction

$$
\text { Fig.3 } \Omega=22.5^{\circ}, D e=333 \text { (Main Flow) }
$$



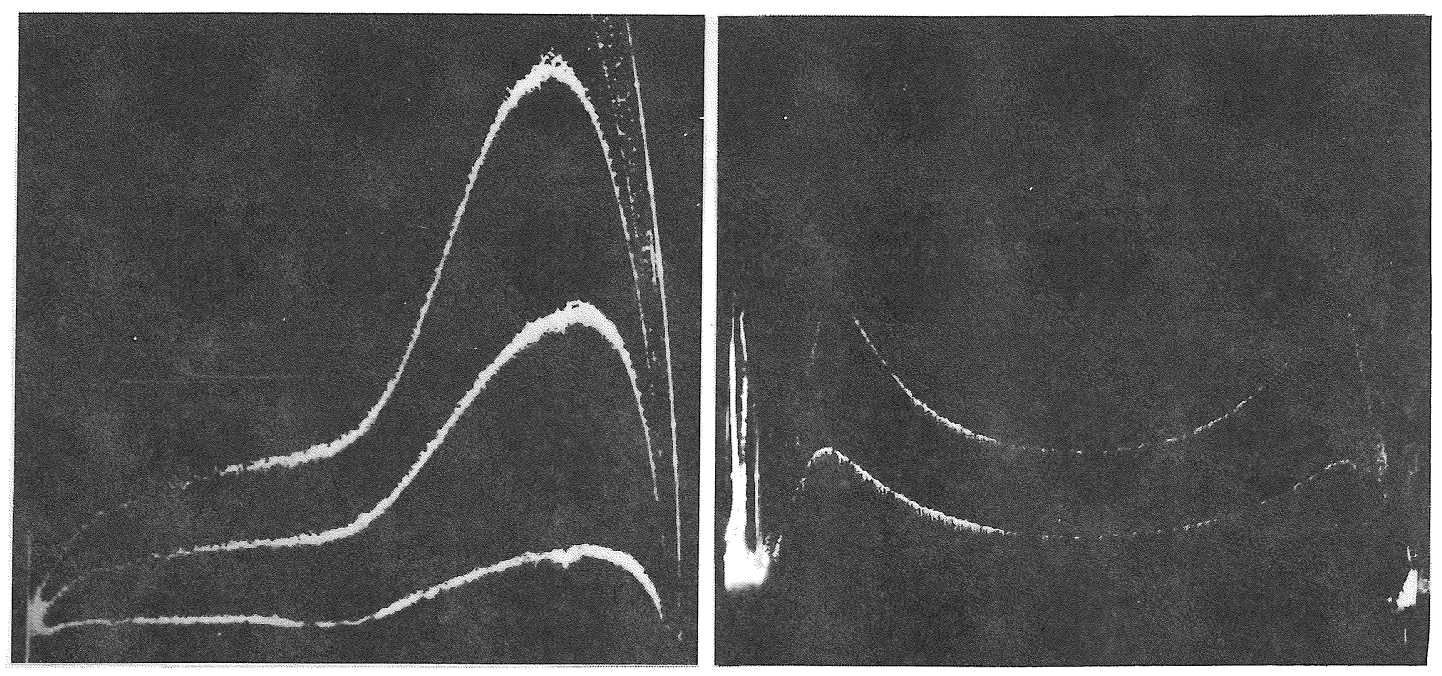

(a) Horizontal Direction

(b) Vertical Direction

$$
\text { Fig.4 } \Omega=45^{\circ}, \mathrm{De}=333 \text { (Main Flow) }
$$

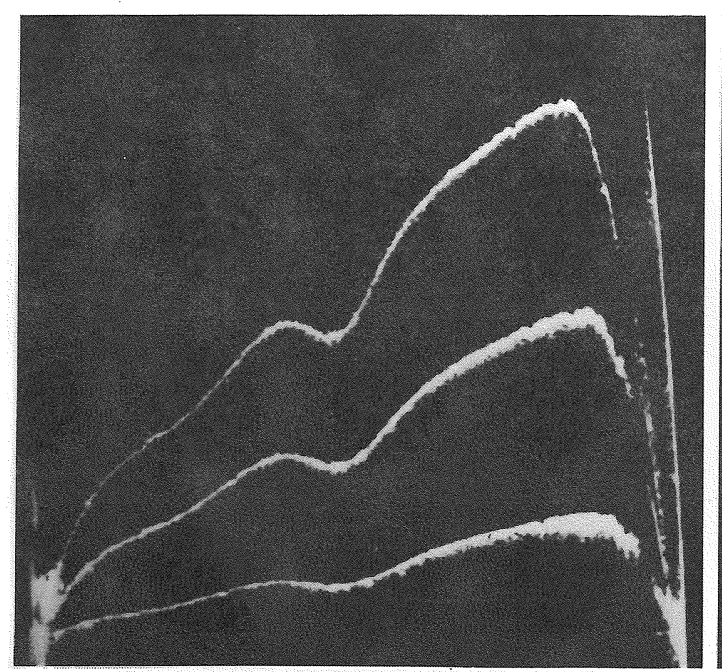

Inner Side
Outer Side Bottom

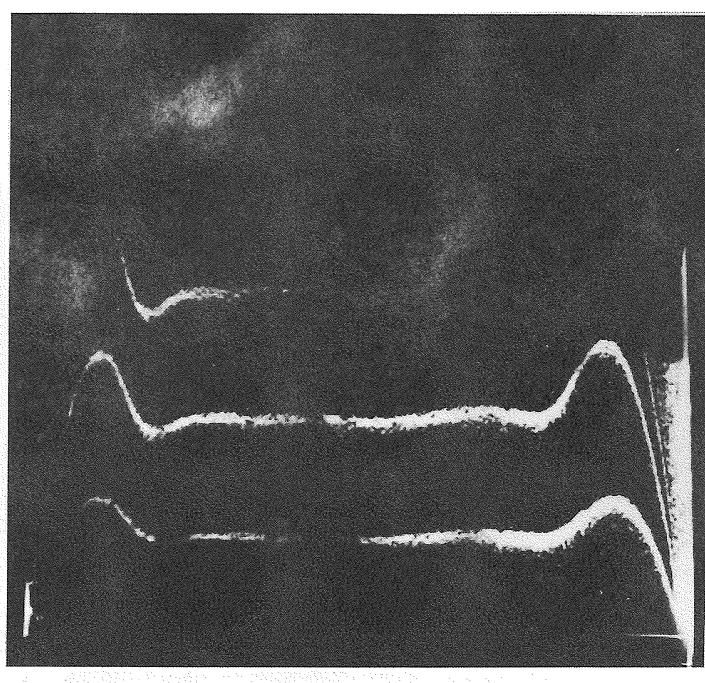

(a)Horizontal Direction

(b) Vertical Direction

$$
\text { Fig.5 } \Omega=90^{\circ}, \quad D e=333 \text { (Main Flow) }
$$


4 二次流水速度分布の結果女考察

了節の主流方向速度分布を示した位 置に対㐫して二次流れ、可視化写真を 图6、7および8に示す。

図6は， $\Omega=22.5^{\circ}$ 力結果で，中央 部の流体が激しい遠心力を受けて急激 に外側の管壁に移動し始凶ていること がわかる。外迥り壁に来た流体は外 迴り中央に淀点を作る。、その点には 遠心力に対峙して压力が形成さ水，粘 性力のた煺心゙力の弱い管壁に沿って 上下二分した流孔が発生し内迴り壁側 に建り这志。二北に上って管内には 一対の二次流以滑が生じる。

图》は， に見ら北るような速い速度部分が減少 して, 如中るい速度、滑を形成して いる。また $\Omega=22.5^{\circ}$ か⿱ $45^{\circ}$ に 故て二次流水滑、中心位置が中央部か らわずかに内迥り側に入ることが知い る。この二次流水は $9 C^{\circ}$ にくをよ ク一層弱まり, 兮までの一対の滑の他 に，新うたに别内非常に骑い一対の福 が現われてくる。次にニか流れが曲

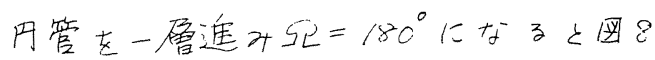
に示可まに流水は安定してくる。

ここで二次流北速度分布の最大速度 は放物形速度をもつ層流入最大值に比

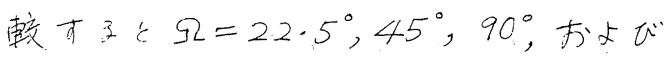
$180^{\circ}$ において，それぞ北20\%15.5\%, 8.5\% おお心゙8.3\%である。

的方少曲丹管内二次流水速度べ

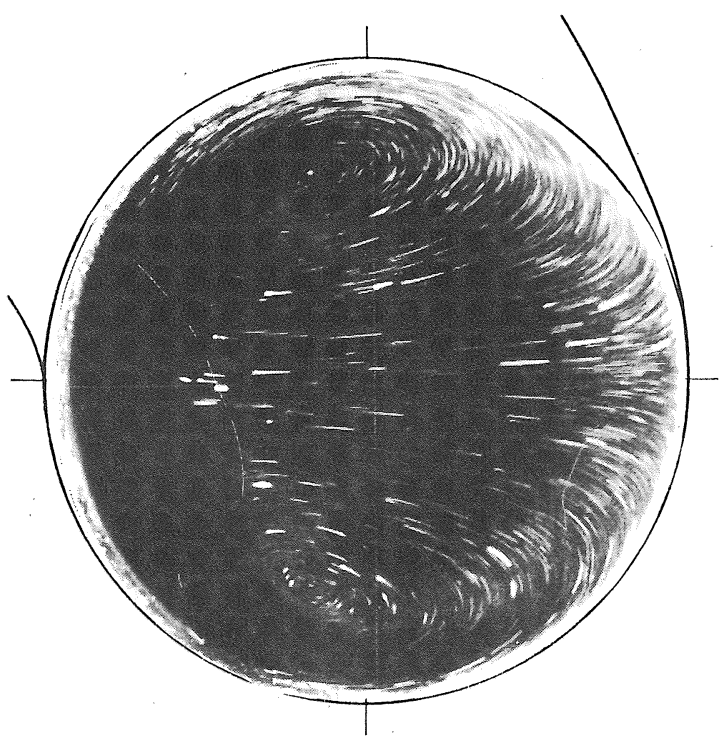

Pig.6 $\Omega=22.5^{\circ}, \mathrm{De}=333$ ( Secondary Flow)

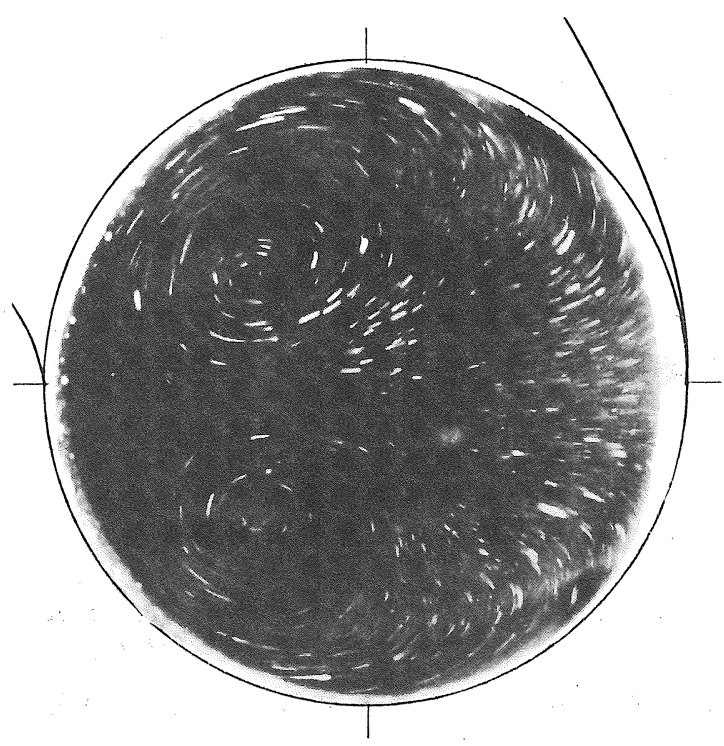

Ais.7 $\Omega=45^{\circ}, \quad D e=333$ (Secondary Flow) クトルを求め計算と比較した結果, それらは良く一致している。

\section{( 二次流风用实験条件)}

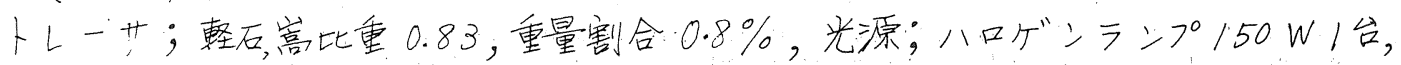
プロジェ7タ-300W2台, 露光; $1 / 2 \mathrm{sec}, F 5.6$, フィルム; ネオパン400 


\section{5 まと女}

直管につブく曲丹管内で発達する層 流について, 速度分布発展の挙動を二 つの可視化法で観察した。实騟条件 は $R_{e}=1000, D_{e}=333, a_{/} R_{c}=1 / 9$ であ る。同一条件での数值解とも直接比 較を行なた。その繥果;

(1) 主流方向速度分布を得るため， 入口かう $0^{\circ}, 22.5^{\circ}, 45^{\circ}, 90^{\circ}$ およむ゙ $180^{\circ}$ の位㯰で水平方向と重直方向につ い下, 水素気泡法を用い夕イムライン を可視化し写真に示した。 $45^{\circ}$ 位置 では主流速度が管中央で極小值をもつ 行き過ぎが見方水た。

（2）上記の写真より主流方向速度分 布を定量化し数值解之良好な一致を故た。

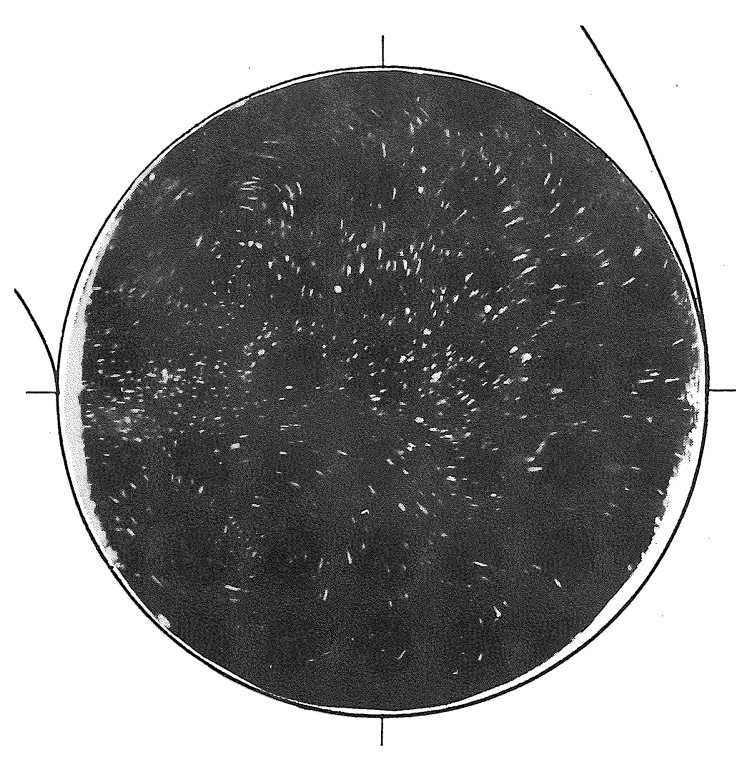

Fig.8 $\Omega=180^{\circ}, \quad \mathrm{De}=333$ ( Secondary Flow)

（3）二次流水速度べクトルや周方向および半径方向速度を求めるた也曲管入口

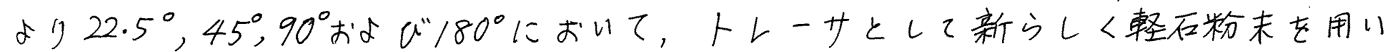
流跡線を可䅐化し，そa写真を示した。900゙は弱い二対目の温の可能性を柇た。

(4) 二次流水速度べクトルを写真より定量化し, かっ数值解と比較してほぼ度 い一致を示した。

宇都宫大学教授西胁一郎先生の御鞭涟を記して感謝致します。また理論討算と 本实驗装置設动は十ヨ夕自工高村伸一氏(元修士学生)に尝うところが大きい。

\section{(参考文献)}

1) Austin,L.R. ; The Development of Viscous Flow within Helical Coils, Ph.D. thesis, University of Utah, 1971

2)三仮喜晴等水素気泡法による曲管内層流の可視化と速度分布測定， 流水の可視化シンポジウム(第2回)，1974，PP.139-142

3) Patankar,S.V. et; Prediction of Laminar Flow and Heat Transfer in Helically Coiled Pipes, al.

J. Fluid Mech.,Vol.62,Part3,1974, pp. 539-551

4)积山光庚ほか; 曲り円管内、速度・温度助走区間における強制・自然褑合熹伝 鈴木正美

5) Akiyama, M. and 蓬，第17回日本伝熱シンポジウム請演論文集，1980,PP。16-18 Takamura, S.et al.

Flow Visualization of the Entrance Rigion for steady Viscous Flow in Coiled Circular Pipes, Int. Symp. on Flow Visualization, Bochum, Sept.o. 1980, pp. 147-151 